\title{
A case of successful organ donation after extremely prolonged manual cardiopulmonary resuscitation in an avalanche victim
}

\author{
Rosanna Varutti, ${ }^{1,2}$ Giulio Trillò, ${ }^{2}$ Adriana Di Silvestre, ${ }^{3}$ Roberto Peressutti, ${ }^{3}$ Flavio Bassi, ${ }^{4}$ \\ Nicola Latronico ${ }^{1}$ \\ ${ }^{1}$ Department of Anesthesia and Critical Care Medicine 2, University Hospital, Brescia; ${ }^{2}$ Helicopter \\ Emergency Medical Service, University Hospital, Udine; ${ }^{3}$ Regional Transplant Center, University Hospital, \\ Udine; ${ }^{4}$ Department of Intensive Care 2, University Hospital, Udine, Italy
}

\begin{abstract}
We report a case of a 41-year-old man, victim of accidental avalanche burial, who donated his organs for transplantation after prolonged cardiopulmonary resuscitation and extracorporeal membrane oxygenation.
\end{abstract}

\section{Introduction}

Due to the difficult procurement of organs for transplantation, new technologies and procedures have been developed, and diagnostic and both outpatient and inpatient therapeutic pathways have been improved.

\section{Case Report}

A 41-year-old man was accidentally buried in an avalanche during a ski trip. The patient had immediate cardiopulmonary resusci-

\footnotetext{
Correspondence: Rosanna Varutti, Helicopter Emergency Medical Service, University Hospital, Piazzale Santa Maria della Misericordia, 33100 Udine, Italy.

E-mail: rosanna.varutti@gmail.com

Key words: Accidental hypothermia; Extracorporeal membrane oxygenation; Avalanche burial; Organ donation.

Contributions: the authors contributed equally.

Conflict of interest: the authors declare no potential conflict of interest.

Funding: none.

Ethical statement: informed consent was obtained from the patient's parents.

Received for publication: 8 June 2019

Revision received: 22 September 2019

Accepted for publication: 22 September 2019.

This work is licensed under a Creative Commons Attribution 4.0 License (by-nc 4.0)

(C) Copyright: the Author(s), 2019

Licensee PAGEPress, Italy

Emergency Care Journal 2019; 15:8338

doi:10.4081/ecj.2019.8338
}

tation (CPR) upon disinterment provided by bystanders; the initially reported avalanche burial was less than $30 \mathrm{~min}$, there were no trunk midsection, decapitation, whole body frozen solid, airway packed with snow nor gasping referred on extrication which are criteria for not starting CPR. The patient was intubated on the field $80 \mathrm{~min}$ after the avalanche, and received $1 \mathrm{mg}$ of adrenaline intravenously because of asystole followed by ventricular fibrillation. After ineffective defibrillation, the decision was made to transport the patient to the Extracorporeal Life Support capable hospital by ambulance with uninterrupted manual CPR because the mechanical compressor device was not available. The end tidal $\mathrm{CO}_{2}$ was maintained 20 and $22 \mathrm{mmHg}$ during all transport time. On arrival to the Emergency Department the tympanic temperature was $20.3^{\circ} \mathrm{C}$. Blood Gas Analysis showed a $\mathrm{pH}$ of 6.6 and a $\mathrm{K}$ of 4.8 $\mathrm{mmol} / \mathrm{L}$, the latter finding suggesting that $\mathrm{CPR}$ had been successful in maintaining effective organ perfusion. Chest and abdomen ultrasound were negative for parenchymal lesions and free fluid, indicating that the cause of cardiac arrest was not traumatic. A mechanical compression device (Autopulse, Zoll Medical, Italy) was applied until femoral artery cannulation was performed; extracorporeal membrane oxygenation (ECMO) started after 75 min from admission to the hospital. The patient was progressively warmed until a return of spontaneous circulation (ROSC) was achieved, 7 hours later, upon reaching $32^{\circ} \mathrm{C}$ (Figure 1). Further inquiry revealed that the initially reported avalanche burial was 60 min. 24 hours after the start of ECMO, a neurological evaluation in normothermia showed the absence of brainstem reflexes. Therefore, death was assessed with neurological criteria in normothermia, as per current Italian law. The patient was declared brain dead. Since the patient had expressed a will of organ donation and the parents were not opposing, the liver and kidneys of the patient were transplanted into 3 recipients. Given the lack of literature to support liver function after a prolonged period of hypothermia, a first hepatologist had expressed a negative opinion despite a normal hepatic biopsy. The liver transplant was then possible after the favorable opinion of a second hepatologist and the informed consent of the recipient, who still enjoys good health.

\section{Discussion}

This case report has several original aspects that deserve di cussion if compared to the International Commission for Mountain Emergency Medicine (ICAR MEDCOM-4) ${ }^{1}$ recommendations and the Italian Programma Alba ${ }^{2}$ for donation after cardiac death. In fact, CPR is not recommended if the burial time is above $60 \mathrm{~min}-$ utes and the body temperature is below $28^{\circ} \mathrm{C} .{ }^{1}$ Moreover, the Programma Alba ${ }^{2}$ suggests that the no-flow time should not exceed 10 minutes and the low-flow time using mechanical compressor 


\section{INTERVENTION TIMES}

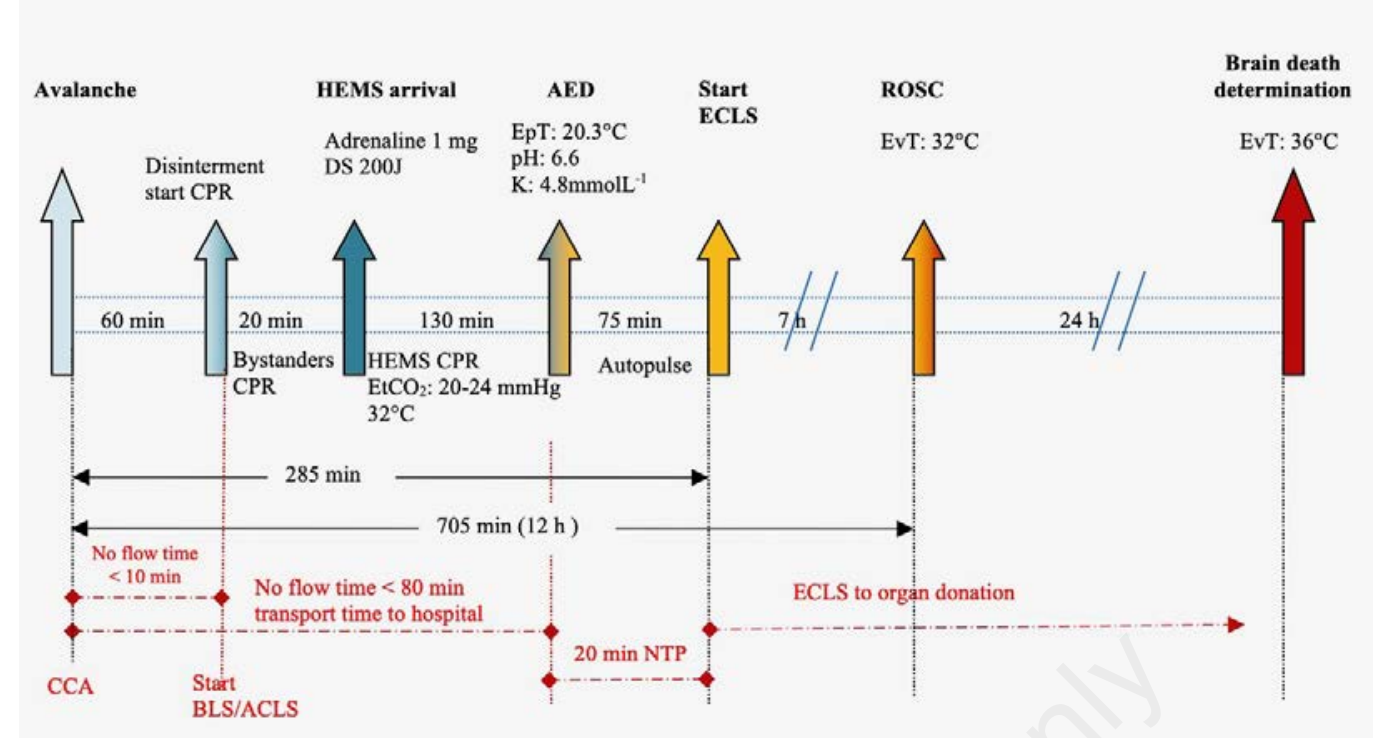

Figure 1. Intervention times. HEMS, helicopter emergency medical service; AED, accident Emergency Department; ECLS, extracorporeal life support; ROSC, return of spontaneous circulation; CPR, cardiopulmonary resuscitation; EpT, epitympanic temperature; EvT, endovascular temperature; $\mathrm{EtCO}_{2}$, end tidal $\mathrm{CO}_{2} ; \mathrm{CCA}$, cardio-circulatory arrest; BLS/ACLS, basic life support/advanced cardiopulmonary life support; NTP, no touch period. In black: case report intervention times. In red: intervention times proposed by the Alba criterion.

should be less than 80 minutes, while these times were 60 minutes and 280 minutes, respectively, in this case. Lastly, the case provides initial evidence of liver resistance under hypothermia conditions. Conceivably, hypothermia played a key role in permitting the successful restoration of circulation and maintenance of organ function. ${ }^{3}$ The evidence available for hypothermia after cardiac arrest is also uncertain as regards pre-hospital induced hypothermia. With rewarming, a ROSC was observed, but not a return of neurological function, indicating an irreversible hypoxic-ischemic brain damage. For this reason we proceeded to a diagnosis of death with neurological and not cardiac criteria, as per current Italian law. 4,5

\section{Conclusions}

The development of new technologies, the application of pathways and therapeutic strategies shared among the various specialties and in the intra-extra-hospital settings, have allowed the recruitment of transplantable and still normal-functioning organs. However, further research is needed in this area.

\section{References}

1. Paal P, Gordon L, Strapazzon G, et al. Accidental hypothermia - an update. Scand J Trauma Resusc Emerg Med 2016;24:111 31.

2. Programma Alba 2.0. Pavia, Italy: Fondazione IRCCS Policlinico San Matteo; 2015.

3. Carter TI, Bodzin AS, Hirose H, et al. Outcome of organs procured from donors on extracorporeal membrane oxygenation support: an analysis of kidney and liver allograft data. Clin Transplant 2014;28:816-20.

4. CNT. Donazione di organi a cuore fermo (DCD) in Italia. Raccomandazioni operative. Documento del Centro Nazionale Trapianti. Rome, Italy: Centro Nazionale Trapianti, Istituto Superiore di Sanità; 2015.

5. CNT. Criteri clinici e raccomandazioni pratiche inerenti l'accertamento di morte in soggetti sottoposti ad assistenza circolatoria extracorporea. Documento del Centro Nazionale Trapianti. Rome, Italy: Centro Nazionale Trapianti, Istituto Superiore di Sanità; 2015. 